UDC 378.046.4

DOI: $10.17223 / 24109266 / 5 / 8$

\title{
DIRECTIONS OF LINGUISTIC EDUCATION INFORMATIZATION
}

\author{
P.V. Sysoyev \\ Sholokhov Moscow State University for Humanities, Derzhavin Tambov State University \\ (Moscow, Tambov, Russian Federation). \\ E-mail: psysoyev@yandex.ru
}

\begin{abstract}
This paper addresses the issue of informatization of linguistic education. The author a) denotes the conditions of informatization of foreign language education, b) defines the main directions of informatization of language education, c) considers the prospects of development of these areas. Under main directions of linguistic education informatization the author proposes the following: a) development of methodology for the selection of teaching content, development of methods and forms of teaching foreign languages; $b$ ) selection of the content of teaching; c) selection of methods and forms of teaching foreign languages and culture; d) development of new innovative methods of using information and communication technologies in teaching foreign languages and culture; e) development of new generation teaching materials, which integrate various ICT in the process of teaching foreign languages and culture; f) development of systems of computer control of the development of students' language skills and abilities; g) setting up a system of teacher training to use ICT in language teaching; h) development of conditions for keeping students' information security.
\end{abstract}

Keywords: informatization of education; information and communication technologies; language education.

\section{Introduction}

The current stage of development of the Russian education system is characterized by its dynamic informatization. The transition to a new paradigm of education from "learning for life" to "learning throughout life", the development of skills of independent educational and cognitive activity and self-education, and the introduction of the competence-based education model focused on the practical use of knowledge, skills and abilities led to a new look at the education process as a process of acquiring strategies for the active accumulation and processing of information with a view of its further practical application. Informatization includes the whole range of measures from the computerization of schools and the development of software to the formation of information culture of the students.

In this regard, I.V. Robert interprets informatization of education in the broad sense of the term as "purposefully organized process of providing the sphere of education with the methodology, technology, and practice of creation and optimal use of the research and pedagogical, educational and methodical findings focused on the realization of the opportunities of the 
information and communication technologies (ICT) used in the comfortable and health-saving environment" [1: 105].

Linguistic education is an integral part of the general secondary, special secondary and higher professional education in Russia. In this connection, computerization of linguistic education in general is carried out along the same lines as the other branches of knowledge. At the same time, foreign language as an academic discipline has its own specifics distinguishing it from the other humanitarian disciplines. Therefore, for the methodical purposes it's necessary to single out and to consider the main trends of information in relation to linguistic education, accentuating the peculiarities of a foreign language as a subject. In the methodology of foreign language teaching the informatization of linguistic education is interpreted as a set of measures to provide the whole process of learning and acquiring foreign language and culture of the target language country with the methodology, technologies to develop new educational and teaching materials, methods to use the new information and communication technologies in education, training and retraining of teachers capable for extensive practical use of the potential of information technologies under health-saving conditions [2]. This definition helps to identify the following eight major areas of the informatization of linguistic education.

1. Establishing the methodological framework for the choice of education content, development of methods and forms of teaching foreign languages and cultures under informatization of linguistic education.

The methodology is interpreted as a set of cognitive tools, approaches, methods and techniques used in the methods of foreign language teaching. The dominant approaches to teaching language and culture under informatization of education will be the following: competence, personal-pragmatic, communicative and cognitive, socio-cultural and multicultural approaches. Competence and personal-pragmatic approaches are the general scientific approaches which characterize the implementation of a specific model of education, including the teaching of certain disciplines. Communicative and cognitive, socio-cultural and multicultural approaches are specific approaches representing the specifics of teaching particularly the foreign language and culture of the target language. In particular, cognitive approach which presupposes acquiring foreign language and culture of the target language country as a result of conscious assimilation of necessary knowledge for the use of language and development on their basis the oral skills, was developed and interpreted within the framework of communicative and cognitive approach introduced by A.V. Schepilova [3]. From the viewpoint of this approach, the educational process should be organized in line with the activity-oriented teaching to solve communicative and cognitive tasks involving considerable amount of comparative methods of language teaching, high level of students' autonomy in choosing the means and strategies of teaching. 
Communicative and cognitive approach presupposing improvement of cognitive abilities of the students effectively implements the developmental potential of the multilingual communication, promoting formation of the students' meta-linguistic awareness - the ability of the students to think about the form, function and nature of the language at the various levels [3: 14].

The socio-cultural approach to foreign language teaching introduced by V.V. Safonova [4] aims to develop the student's identity as a cultural and historical entity, the bearer of group and individual socio-cultural characteristics and his role as a subject of cultures, integrative general cultural and communicative skills to use a foreign language as a means of intercultural communication. According to this approach, socio-cultural education should be implemented on a widening range of cultures (from the ethnic, superethnic cultures, social subcultures to the geopolitically marked regionalcontinental cultures and world culture) and in the context of their dialogue. The methodological dominant in this approach is the system of problematic culturological tasks aimed at the use of foreign language and sociocultural competence in the situations of intercultural communication [4: 63]. Sociocultural approach was further developed in the multicultural approach to teaching foreign language and culture introduced by P.V. Sysoyev [5-7]. Linguistic multicultural education involves the cultural diversity of the thematic content of the teaching materials in foreign languages and language courses for every type of culture (ethnic, social, religious, professional, territorial, etc.), thus creating favorable conditions for the multicultural development of the students. With this approach the students will develop an idea of cultural diversity as a normal coexistence of cultures in the modern multicultural communities of the countries of native and target languages. Costudying of cultures of the modern multicultural communities of the countries of native and target languages would promote the broadening of sociocultural space and cultural self-identification of the students (identifying his place in the spectrum of cultures), as well as the development of the ability to take an active part in the struggle against the cultural aggression, cultural vandalism and cultural discrimination.

The subject-object relations in which the student is perceived as a passive recipient of knowledge, changed by the subject-subject relations: the student became an active participant of the educational process capable to use his knowledge in practice, to recognize the value of the acquired knowledge and developed skills, to understand the need for self-education throughout their lives and, thus, to be competitive in the modern ever changing labor market. In this regard, the competence-based approach does not change the overall personal and pragmatic orientation of the education, but on the contrary, emphasizes it, focusing on the practical component of students' activities and on the outcomes. 
It should be noted that the term "competence approach" has been introduced in pedagogics only recently, but in the methodology of foreign language teaching the focus of the educational process on the outcome - communication in the language with the representatives of different countries and cultures in terms of "communicative competence" - for several decades stands out as one of the basic goals of foreign language teaching.

Thus, the methodological basis of the informatization of the linguistic education is not entirely new and hitherto unknown in the methodology of foreign language teaching. However, due to their didactic properties new information and communication technologies contribute to better implementation of these approaches in practice. If under the traditional model of interaction "teacher-student" much depended on the personality of a teacher more or less capable to go to the person-oriented model of teaching, the new information technologies provide the teachers no choice but to implement the methods of active teaching, to create the individual trajectories of training and to support the autonomous educational activity of the students.

Complete implementation of the all mentioned approaches while identifying the purpose and effect, the choice of contents, methods and forms of teaching contributes to the training, education and personal development of a student by means of a foreign language and culture of a target language country under informatization of education.

\section{The choice of content of teaching foreign language and culture under informatization of linguistic education}

Modern academic and nonacademic (authentic) Internet resources create favorable conditions for the development of cognitive activity of the students. The use of the modern ICT in the educational process will help to develop the ability to search, select, evaluate, classify, summarize and present new information. Certainly, the development of the skills of cognitive activity in the process of teaching foreign language and culture at the higher school will contribute to the development of the skills of autonomous learning in the field of foreign language teaching throughout life.

Language database (linguistic corpus) and multimedia Internet resources on the culture (cultures) of the target language country (thematic web sites, online encyclopedia, virtual tours of galleries and museums) can greatly enrich and expand the linguistic and cultural practices of the students. The whole palette of the modern Internet resources creates the didactic basis for the linguistic multicultural education: formation of ideas about the cultural and linguistic diversity of the countries of native and target languages [8]. The thematic content of the curriculums can go far beyond the existing curriculums and teaching materials, the students can acquire the different variants of the target language used in the social and cultural contexts. 
Social services, Web 1.0 services (e-mail, web forum) and Web 2.0 services (wikis, blogs, podcasts) allow organizing network interaction among all the participants of the educational process, including in a foreign language. Moreover, social services and Internet services can serve as platforms for the implementation of telecommunication projects, partners in which may be the students from different countries. At the same time, along with the formation of foreign language communicative competence, the real purpose of linguistic education will be the formation of the intercultural competence of the students, their ability to contact with the representatives of other countries and cultures, recognizing their cultural identity.

Thus, the content of teaching foreign language and culture under informatization of linguistic education should be focused on a) the development of students' motivation to learn a foreign language and to use it to obtain the necessary information and to communicate with the representatives of different countries and cultures by the new information and communication technologies; $b$ ) the formation of foreign language communicative competence in the receptive (listening, reading) and productive (writing, speaking) types of speech activity; c) the formation of intercultural competence; d) development of cognitive activity of the students; e) development of skills of autonomous learning; f) development of reflective activity of the students. The development of the all mentioned aspects occurs comprehensively, where every aspect is a part of an integral mechanism for training, education and personal development of a student.

\section{The choice of methods and forms of teaching foreign language and culture under informatization of linguistic education}

Methodological basis determines the choice of methods and forms of teaching foreign language and culture under informatization of education. The changes in the methods of teaching foreign language and culture are conditioned by the transition from the subject-object to the subject-subject model of teaching. In the traditional subject-object model of educational interaction between the teacher and learner the tutors widely use the information and receptive and reproductive methods of teaching in which the students are treated as the passive recipients of information. Their main task is to receive from the teacher the certain amount of knowledge and to memorize it. The transition to the subject-subject model of teaching involves the active use of the method of problem-based learning, the heuristic method and the research method [9]. These methods allow under conditions of informatization of education to use widely the distant forms of teaching: access to the bulk of the target material, interactive communication of the students and teachers in the education process, providing students with the pos- 
sibility for self-education to adopt the target material, as well as in the educational process by means of information and communication technologies.

The implementation of the methods of active teaching under conditions of informatization of education allows complete using of the didactic potential of the information and communication technologies in the development of students' self-education skills. Under the self-educational activity, according to N.F. Koryakovtseva, we should understand "the kind of cognitive activity regulated and controlled by the student as a subject of this activity and aimed at the development of subject knowledge and skills and the cultural and historical experience" [10: 14]. Participation in the autonomous productive educational activity means that the student:

- participates in the specification of the objectives of foreign language teaching and correlates them with his real interests and needs;

- actively participates in projecting the outcomes of foreign language teaching and identifying criteria for its evaluation;

- together with the teacher and his fellow students chooses the most appropriate and effective forms and methods of training;

- monitors the process and success of his language acquisition;

- evaluates the real achievements and the possibilities for the use of foreign language in practice;

- evaluates the productivity and experience of his educational activity;

- evaluates himself, defines "me-position" [Ibid: 16].

At the first stage the organization of autonomous educational activity of the students may be carried out according to the proposed algorithm with the clearly identified stages and roles of the each member of the educational process. At the advanced stage, the students will develop their own individual trajectory of the project, solve the proposed educational task. It involves the formulation of the problems the solution of which will lead to achieving the goal, hypothesis formulation, choosing the methods to solve the problem, developing algorithm, conclusions, evaluation and reflection.

It should be noted that from the viewpoint of didactics the mentioned above active methods of teaching correlate with the communicative method of foreign language teaching, focused on the formation of foreign language communicative competence of the students - proficiency in a foreign language as a means of communication.

\section{Developing innovative methods of using ICT in teaching foreign languages and cultures}

Certainly, the implementation of the new information and communication technologies in the educational process requires the development of the new and innovative methods of teaching foreign language and culture of the target language country under informatization of education. At the same 
time it is important to realize that the use of a specific resource or Internetbased technology for the development of specific types of speech activity or for the formation of socio-cultural and intercultural competences should be conditioned not by the general trend of "teaching everything by ICT" but by the adequacy, efficiency and usability of using this Internet technology to solve a specific educational task! As an example, consider the development of the ability to write personal letters. To develop writing skills we can use both blog-technologies [11] and wiki-based technologies [12]. In the blogs only one person may appear as the author of the post. Other project participants can get acquainted with his written statement and participate in the network discussion. Wiki technology exists to create a single document by several people. Because in the real life the author of the personal letter is one person, to develop this writing skill it would be appropriate to use blog technology. To address the same problem by wiki technology would be inauthentic and non-communicative.

Despite the fact that ICT was introduced into the methodology of foreign language teaching just recently, however, in the scientific and educational literature it has already formed a considerable corpus of works in which the authors developed methods of teaching language skills, types of speech activities and culture by means of a certain Internet-technology and identified the efficiency of its use in the educational process. In particular, recently they have developed the following techniques:

- using educational Internet resources in foreign language teaching (M.N. Evstigneev, P.V. Sysoyev) [13];

- using e-mail group for the formation of intercultural competence of the students $[14,15]$;

- using web forum and blog-technology for the development of writing skills and for the formation of sociocultural competence [11, 16-18];

- using wiki technology for the development of students' writing skills $[12,19,20]$

- using podcasts for the development of listening and oral skills of the students [21];

- using linguistic corpus in the formation of the linguistic oral skills [22].

According to the student-centered approach the choice of a particular technology or methods of teaching foreign languages and cultures should be carried out taking into account the interests, needs, abilities, motivations of a particular group of students.

\section{Developing teaching materials of a new generation, integrating different kinds of ICT in the process of foreign language teaching}

Didactic opportunities of the modern information and communication technologies make it possible to restructure the presentation of teaching ma- 
terial. At the moment, along with the traditional textbooks students can use educational Internet resources - resources created by the teacher for the training purposes on the target topic: hotlist, multimedia scrapbook, treasure hunt, subject sample, web quest [13]. These resources are already known to most teachers, they are simple to create using network software Filamentality.

In the long term the textbook in a foreign language with the linear form of presentation will be replaced by the electronic, multimedia, interactive tutorial having a hypertext and interactive structure. In addition to textual information (although it can be developed entirely on external resources) with the internal and external links to the Internet resources, it will contain illustrative material, audio and video podcasts, will be able to provide access to a "virtual reality". Access to the external Internet resources on the target topics allows students to develop cognitive activity and significantly enriches their linguistic and cultural practices. Interactive tests precisely indicate the student his problem areas and redirect to the appropriate resources. The multilevel nature of the future textbook allows students choosing individual educational trajectory.

\section{Developing systems for the computer-based control of oral skills and formation of language skills of the students}

Developing systems for the computer-based control of oral skills and formation of language skills of the students is another innovative direction of the informatization of linguistic education. At the modern stage there is a software that allows you to implement communicative control of the development of the forms of speech activity, and not only receptive types (listening and reading), but also productive (writing). The international standardized language exams, in particular, the computer version of TOEFL (Test of English as a Foreign Language) can serve as examples of the wide use of the software of this kind. However, despite the high reliability, some of the tasks of the computer-based tests raise questions among the scientists-methodologists. In particular, the criteria for evaluation of an essay in the computer version of the TOEFL test are as follows: strict adherence to the format of a written statement (introduction, main part, conclusion) and the use of the words-connectors. And the most important - the content of the work and the depth of the thoughts of a written statement - can't be assessed by a computer. Nevertheless, it is a modern experience of using computer technology in the evaluation of oral skills, which, of course, will be improved and in the nearest future will meet the needs of the students and modern methodological requirements. Besides, within the framework of this trend the electronic versions of the alternative testing methods (e.g. e-portfolio) should be developed. 


\section{Organization of the system for training and retraining of the teachers in the field of informatization of linguistic education}

Training and retraining of the teachers under informatization of linguistic education is one of the most relevant trends of informatization of education, because the impossibility to introduce the modern ICT into the educational process of teaching foreign language and culture is conditioned by the inability or rather incompetence of the teachers in the use of modern ICT in the educational process. In this regard, there is an urgent need for relevant training courses and retraining of teachers. Currently, many Institutes of Professional Education in the various regions of the country offer such courses, where the teachers of different disciplines are enlisted in the same group. It should be emphasized that the content of training within this program must necessarily include both invariant component (relevant for the teachers, regardless of the profile) and variable component (focusing on the use of ICT while teaching a specific discipline). For example, the invariant component may contain information on the didactic features of the social services and Web 2.0 services. Within the framework of the variable component the foreign language teachers become familiar with the specific oral skills that can be developed on the basis of each of the Web 2.0 services (blogs, wikis, podcasts), and examine the methods for the formation of the components of the foreign language communicative competence by a particular service. It should be noted that Russian scientists carried out a serious work to prepare the training programs for the teachers in terms of informatization of education. I.V. Robert, S.V. Panyukova, A.A. Kuznetsov and A.Y. Kravtsova [23] developed an invariant part of the refresher course, including general didactic issues. The variable part of the course (in relation to the foreign language teachers) which represents the specifics of teaching a foreign language by the new ICT is represented in the works by P.V. Sysoyev and M.N. Evstigneev [24, 25].

However, the re-training should not be limited by the one course. There are online communities of subject teachers from the different regions of Russia, where they can get acquainted with the experience of the others and share their own experiences of using one or another Internet-based technology in teaching, participate in the online conferences, video conferences, discussions on the professional forums, etc. One of such communities is the Association of e-Learning Pro specialists which integrates the professionals in the sphere of distance learning. Participating in the discussion of the topical issues of computer pedagogy, the teachers will constantly improve their professional competence and thus implement in practice one of the basic postulates of the XXI century - "Learning throughout life"! 


\section{Developing measures to ensure information security of the students}

Along with the many benefits offered by the modern Internet environment to the educational process it can also lead to negative consequences for any Internet user. Experience of implementing the models of distance education shows the variety of the forms of moral and material damage which the interaction in the Internet environment may cause to the students. Here are just a few examples relevant for the pupils and students:

- Using personal data of the users (passport details, dates of birth, bank account information, addresses, phone numbers, etc.) by the Internet scams to register loans, to make purchases, online payments, to blackmail.

- Visiting sites intended for adults $(18+)$ may contribute to child molestation.

- Loading untested programs and viruses can disable the operating system and computer data.

- Network communication with the strangers can lead to undesirable consequences.

- Excessive use of the Internet entertaining resources (online games) can lead to Internet addiction of the adolescents.

\section{Conclusion}

In this regard, there is an urgent need to train the students in the field of information security just before the implementation of the Internet projects and the organization of network education through social services and Web 2.0 services. The students will be ready for the real secure network communication in the native and target languages as far as we can teach them network communication in the educational process [26].

Therefore, the modern Internet environment, along with the undeniable advantages, carries a specific risk that must be considered in the development of foreign language teaching methods based on the new information and communication technologies. It is obvious that in the nearest future the integration of the modern information and communication technologies into the foreign language and culture teaching creates didactic backgrounds for teaching pupils and students on individual trajectories, taking into account their interests, needs and abilities [27, 28]. All mentioned above areas of the informatization of linguistic education are in close connection. Informatization of education, including linguistic education, is an irreversible comprehensive process in which each teacher should find his place and determine his share of responsibility for the development of students' skills for education and self-education in the ever-changing world of new technologies and developments. 


\section{References}

1. Robert, I.V. (2010) Modern information technologies in education: didactic problems, and use perspectives. Moscow: Rossijskaya akademiya obrazovaniya.

2. Sysoyev, P.V. (2012) Informatization of foreign language education: main directions and perspectives. Foreign Languages at School. 2. pp. 2-9.

3. Shchepilova, A.V. (2003). Communicative-cognitive approach to teaching French as a second foreign language. Unpublished Doctoral dissertation. Moscow: Rossijskaya akademiya nauk.

4. Safonova, V.V. (1996) Learning languages of international communication in the context of dialogue of cultures and civilizations. Voronezh: Istoki.

5. Sysoyev, P.V. (2003a) Theory of foreign language polycultural education. Moscow: Euroschool Press.

6. Sysoyev, P.V. (2003b) Cultural identity as a part of learners' polycultural education in Russia via a native and a foreign language. Foreign Languages at School. 1. pp. 42-48.

7. Sysoyev, P.V. (2006) Foreign language multicultural education. Foreign Languages at School. 4. pp. 2-14.

8. Sysoyev, P.V. (2012) Modern information and communication technologies: didactic characteristics and functions. Language and Culture. 1 (17). pp. 120-133.

9. Skatkin, M.N. \& Lerner, I.J. (1975) Didactics in secondary school. Moscow: Politizdat.

10. Koryakovtseva, N.F. (2002) Modern methods of organizing individual work of foreign language students. Moscow: ARKTI.

11. Sysoyev, P.V. (2012). Blogs in foreign language teaching. Language and Culture. 4 (20). pp. 115-127.

12. Sysoyev, P.V. (2013) Using wiki in teaching a foreign language. Language and Culture. 3 (23). pp. 140-152.

13. Sysoyev, P.V., Evstigneev, M.N. (2010) Methods of teaching a foreign language by means of new information and communication Internet-technologies. Moscow: Glossa press.

14. Apalkov, V.G. (2008) Technique of formation of intercultural competence by means of email group (English, profile level). Philology Dr. Diss. Tambov.

15. Sushkova, N.A. (2009) Methods of the development of students' intercultural competence in immersion. Philology Dr. Diss. Tambov.

16. Borshcheva, O.V. (2013) Methods of the development of learners' sociocultural skills via modern Internet technologies. Philology Dr. Diss. Moscow.

17. Cherkasov, A.K. (2012) Nomenclature of sociocultural skills, developed via webforum. Language and Culture. 1 (17). pp. 134-139.

18. Sysoyev, P.V., Pustovalova O.V. (2014) Developing writing skills with "Twitter". Language and Culture. 3. pp. 128-136.

19. Evstigneeva, I.A. (2014). Development of learners' discourse skills via modern information and communication technologies. Foreign languages at School. 2. pp. 17-21.

20. Markova, Y.Y. (2010). The development of students' writing skills by means of Wiki service. Language and Culture. 1 (9). pp. 85-91.

21. Sysoyev, P.V. (2014). Podcasts in teaching a foreign language. Language and Culture. 2 (26). pp. 189-201.

22. Sysoyev, P.V., Kokoreva, A.A. (2013) Teaching professional terms to EFL students using parallel corpus. Language and Culture. 1 (21). pp. 114-124.

23. Robert, I.V., Panukova, S.V., Kuznetsov, A.A. \& Kravtsova, A.Y. (2008) Information and communication technologies in education. Moscow: Drofa.

24. Sysoyev, P.V., Evstigneev, M.N. (2014) Foreign language teacher's competence in using information and communication technologies. 1. pp. 141-147. 
25. Evstigneev, M.N. (2013) Genesis and variability of conceptual content of education informatization terms. Language and Culture. 1 (21). pp. 63-73.

26. Sysoyev, P.V. (2011) Information security of L2 learners in Internet educational environment: modern response to challenges. Foreign Languages at School. 10. pp. 16-20.

27. Sysoyev, P.V. (2014a) Individual education path: what is it? Foreign Languages at School. 3. pp. 2-12.

28. Sysoyev, P.V. (2014b) A system of teaching foreign languages based on individual ways by means of modern ICTs. Foreign Languages at School. 5. pp. 2-11. 